\title{
Periodic Mechanical Stress Activates PKCס- Dependent EGFR Mitogenic Signals in Rat Chondrocytes via PI3K-Akt and ERK1/2
}

\author{
Peng He ${ }^{a}$ Nan Shen ${ }^{b}$ Gongming Gao ${ }^{c}$ Xuefeng Jiang ${ }^{d}$ Huiqing Sun ${ }^{d}$ Dong \\ Zhou $^{c}$ Nanwei Xuc Luming Nong ${ }^{c}$ Kewei Ren ${ }^{d}$ \\ aDepartment of Orthopedics, Jiangyin No 3 People's Hospital, Jiangyin, bDepartment of Clinical \\ Pharmacy, the Affiliated Jiangyin Hospital of Southeast University Medical School, Jiangyin, \\ 'Department of Orthopedics, the Affiliated Changzhou No 2 Hospital of Nanjing Medical University, \\ Changzhou, 'Department of Orthopedics, the Affiliated Jiangyin Hospital of Southeast University \\ Medical School, Jiangyin, China
}

\section{Key Words}

Chondrocyte proliferation - EGFR $•$ Periodic mechanical stress $\cdot$ PI3K-Akt $•$ PKC $\delta$

\begin{abstract}
Background/Aims: The present study aimed to analyze the mechanisms by which periodic mechanical stress is translated into biochemical signals, and to verify the important role of signaling molecules including phosphatidylinositol-3-kinase (PI3K)-Akt, protein kinase $C$ (PKC), and epidermal growth factor receptor (EGFR) in chondrocyte proliferation. The effects of periodic mechanical stress on the mitogenesis of chondrocytes have been studied extensively in recent years. However, the mechanisms underlying the ability of chondrocytes to sense and respond to periodic mechanical stress need further investigation. Methods: Two steps were undertaken in the experiment. In the first step, the cells were pretreated with shRNA targeted to Akt or EGFR or PKC $\delta$ or control scrambled shRNA. Moreover, they were pretreated with LY294002, GF109203X, Gö6976, rottlerin, and AG1478. They were maintained under static conditions or periodic mechanical stress for 3 days, $8 \mathrm{~h}$ per day, prior to direct cell counting and CCK-8 assay, respectively. In the second step, the cells were pretreated with shRNA targeted to Akt or EGFR or PKC $\delta$ or control scrambled shRNA. Moreover, they were pretreated with LY294002, AG1478, and rottlerin. They were maintained under static conditions or periodic mechanical stress for $1 \mathrm{~h}$ prior to Western blot analysis. Results: Proliferation was inhibited by pretreatment with PKC or PKC $\delta$ inhibitor GF109203X or rottlerin and by short hairpin RNA (shRNA) targeted to PKC $\delta$, but not by PKC $\alpha$ inhibitor Gö6976 in chondrocytes in response to periodic mechanical stress. Meantime, rottlerin and shRNA targeted to PKC $\delta$ also attenuated EGFR, Akt, and ERK1/2 activation. Furthermore, inhibiting EGFR activity by AG1478 and shRNA targeted to EGFR abrogated chondrocyte proliferation and phosphorylation levels of Akt and extracellular signal-regulated kinase (ERK)1/2 subjected to periodic mechanical stress, while the phosphorylation site of PKC $\delta$ was not affected. In addition, pretreatment with the PI3K-Akt-selective inhibitor LY294002 and shRNA targeted to Akt reduced periodic

P. He and N. Shen - Co-first author.

Luming Nong

and Kewei Ren

Department of orthopedics, the Affiliated Changzhou No 2 Hospital of Nanjing Medical University, 29 Xinglongxiang, Changzhou 213003, (China); Department of orthopedics, the

Affiliated Jiangyin Hospital of Southeast University Medical School, 163 Shoushan Road,

Jiangyin 214400, (China); E-Mail lumingnong@hotmail.com / keweiren@hotmail.com
\end{abstract}

KARGER 
He et al.: PKC $\delta$-Dependent EGFR Mitogenic Signals via PI3K-Akt and ERK1/2

mechanical stress-induced chondrocyte proliferation and phosphorylation of ERK1/2, while the phosphorylation levels of EGFR and PKC $\delta$ were not inhibited. Conclusion: These findings suggested that periodic mechanical stress promoted chondrocyte proliferation through PKC -EGFR-PI3K-Akt-ERK1/2. They provide a stronger viewpoint for further investigations into chondrocyte mechanobiology under periodic mechanical stress and the ways to improve the quality of tissue-engineered cartilage.

\section{Introduction}

Periodic mechanical stress is advantageous to simulate in vivo physiological conditions for promoting chondrocyte proliferation [1, 2]. However, few studies have addressed the mechanisms underlying the translation of such mechanical inputs into biochemical signaling events within the chondrocyte lineage.

Phosphatidylinositol-3-kinase (PI3K) is a family of enzymes that can generate phosphoinositides that anchor kinases to the cell membrane to form signaling aggregates, activating multiple downstream intracellular signaling cascades [3-5]. PI3K-Akt signals activation has been shown to regulate the mitogenic responses to mechanical stimuli from the cellular peripheral environment [6]. Gayer and colleagues proved that mechanical-shear induced repetitive deformation stimulated the proliferation of intestinal epithelial cells through PI3K-Akt signals [7]. However, no study demonstrated the mitogenic effects of PI3KAkt signals in chondrocytes in response to mechanical stimulation.

Protein kinase $\mathrm{C}$, also known as $\mathrm{PKC}$, is a family of protein kinases involved in controlling the activation of downstream signaling proteins [8]. PKC signals can be activated by multiple stimuli including mechanical stimulation and these pathways can mediate multiple cellular biological activity and functions $[9,10]$. A study by Liu confirmed that intermittent mechanical strain-enhanced fetal lung cell proliferation was dependent on activated PKC [11]. Meanwhile, some previous studies showed that PKC activation modulated cell behavior and functions via enhancing PI3K-Akt activity [12]. However, it is presently unclear whether PKC is involved in modulating mechanical stress-initiated mitogenic effects in chondrocytes, and which specific isoforms of the PKCs are involved in this process. Moreover, the nature of the relationship between PKC and PI3K-Akt remains to be elucidated.

Epidermal growth factor receptor (EGFR) is a member of a larger superfamily of receptor kinases with intrinsic tyrosine kinase activity. EGFR can interact with and activate various potential downstream signaling molecules and intracellular signal transduction pathways, thereby eliciting various cellular responses including proliferation, differentiation, and migration $[13,14]$. EGFR can be activated by mechanical stimuli. Yano et al demonstrated that mechanical stretching induced proliferative signals on human keratinocytes via EGFRextracellular signal-regulated kinase (ERK)1/2 $[15,16]$. EGFR has been shown to play important roles in the modulation of chondrocyte activity and functions following chemical stimuli $[17,18]$. Moreover, the relationship among EGFR, PKC, and PI3K has been alluded to in some studies concerning signaling transduction of other cells $[19,20]$. Following periodic mechanical stress, the role of EGFR in mechanosensing, signaling transduction, and final mitogenic effects in chondrocytes, including the nature of any functional association among EGFR, PKC, and PI3K in this system, is yet to be explored.

This study analyzed the mechanisms by which periodic mechanical stress is translated into biochemical signals and verified the important roles of signaling molecules including PI3K-Akt, PKC, and EGFR in chondrocyte proliferation.

\section{Materials and Methods}

Materials

Two-week-old Sprague-Dawley rats of either sex were provided by the Animal Center of Nanjing Medical University. Dulbecco's modified Eagle's medium-nutrient mixture F-12, fetal bovine serum, trypsin, 


\section{Cellular Physiology Cell Physiol Biochem 2016;39:1281-1294 \begin{tabular}{l|l|l|l|} 
DOI: 10.1159/000447833 & $\begin{array}{l}\text { C } 2016 \text { The Author(s). Published by S. Karger AG, Basel } \\
\text { www.karger.com/cpb }\end{array}$
\end{tabular} \\ He et al.: PKC 8 -Dependent EGFR Mitogenic Signals via PI3K-Akt and ERK1/2}

collagenase II, and anti-collagen monoclonal antibody II were purchased from Gibco (USA). Type II collagen was purchased from Sigma (USA). Cell counting kit-8 (CCK-8) was purchased from Beyotime Institute of Biotechnology (China). Anti-PKC $\delta$, anti-phospho-PKC $\delta$ (Thy ${ }^{507}$ ), anti-EGFR, anti-phospho-EGFR $\left(\mathrm{Tyr}^{1068}\right.$ ), anti-Akt, anti-phospho-Akt (Ser ${ }^{473}$ ), anti-ERK1/2, anti-phospho-ERK1/2 ( $\left.\mathrm{Thr}^{202} / \mathrm{Tyr}^{204}\right)$, horseradish peroxidase-goat anti-rabbit IgG, and enhanced chemiluminescence (ECL) assay kit were supplied by CST Co., Ltd. (USA). LY294002 was purchased from Promega (USA). Rottlerin was supplied by EMD Biosciences (USA). GF109203X, Gö6976, and AG1478 were purchased from Calbiochem (USA). Akt short hairpin RNA (shRNA) lentiviral particles, EGFR shRNA lentiviral particles, PKC $\delta$ shRNA lentiviral particles, Control shRNA lentiviral particles, and Polybrene were supplied by Santa Cruz (USA).

A cell incubator (Hereus BB 5060), air-tight cell culture device and reciprocating pressure pump, barrier-type pressure transducer and inversion microscope equipped with camera system were bought from Hereus (Germany), Taixing Experimental Instrument Factory (China), Tianjin Plastics Research Institute (China) and Olympus (Japan), respectively.

\section{Methods}

Cell culture. Chondrocytes were harvested using the method described by Séguin and Bernier [21]. The cells were purified by repeated adherence, and the morphology was observed under an inverted phase contrast microscope by staining for collagen type II according to the conventional ABC method. The cells of the second generation were seeded on a glass slide $\left(25 \times 25 \mathrm{~mm}^{2}\right)$ coated with type II collagen at a density of $10^{5}$. Experiments were performed when the cells were approximately $70-80 \%$ confluent.

Inhibitors. LY294002, GF109203X, Gö6976, rottlerin, and AG1478 were specific inhibitors against PI3K-Akt, PKC, PKC $\alpha, \mathrm{PKC} \delta$, and EGFR, respectively. All of the inhibitors were dissolved in anhydrous dimethylsulfoxide (DMSO) to form 1000 concentrated solution. All inhibitors were aliquoted and stored at $-20^{\circ} \mathrm{C}$. Each concentrated solution was diluted by $1000 \times$ immediately prior to use; inhibitor pretreatment groups contained $0.1 \%(\mathrm{v} / \mathrm{v})$ DMSO, which was the concentration used for the control group. The cells were pretreated with LY294002 (25 $\mu \mathrm{M})$, GF109203X (10 $\mu \mathrm{M})$, Gö6976 $(10 \mu \mathrm{M})$, Rottlerin $(10 \mu \mathrm{M})$, AG1478 $(5 \mu \mathrm{M})$ or an equivalent amount of DMSO $(0.1 \% \mathrm{v} / \mathrm{v})$ for $1 \mathrm{~h}$.

Construction of a periodical mechanical stress field

A periodic stress field of perfusion culture system with adjustable stress intensity and frequency was built by connecting the reciprocating intensifier pump to the air-tight cell culture device through a barriertype pressure transducer, as previously described [22]. The reciprocating intensifier pump was mainly composed of a compression power device, a piston, and an air-tight pressure chamber filled with a fluid. The compression power device created a mechanical reciprocating motion by connecting with the piston and squeezing the fluid of the air-tight pressure chamber to generate periodic hydraulic pressure, acting on the pressure transducer through the input terminus. The pressure transducer was composed of a diaphragm and a pressure monitor. The diaphragm was located in the middle of the pressure transducer and separated the bilateral fluids of the input terminus and the output terminus, which transmitted the periodic hydraulic pressure produced by compressive deformation of the reciprocating compression pump to the air-tight cell culture device filled with the cell culture medium. The pressure monitor was located in the output terminus of the pressure transducer, permitting monitoring and regulation of hydraulic pressure in real time to maintain a constant intensity and frequency. Hydraulic pressure periodically acted on chondrocytes of the second generation by inoculating them onto the slide in the air-tight cell culture device.

The pressure in this system ranged from 0 to $300 \mathrm{kPa}$ and the frequency from 0 to $1 \mathrm{~Hz}$. Earlier, it was shown that rabbit chondrocytes subjected to stress varying from 0 to $200 \mathrm{kPa}$ at $0.1 \mathrm{~Hz}$ yielded tissueengineered cartilage of the best quality $[23,24]$. Accordingly, a pressure range of $0-200 \mathrm{kPa}$ and $0.1 \mathrm{~Hz}$ frequency were used in the current study.

\section{Experimental grouping}

Two steps were undertaken in the experiment. In the first step, the cells were pretreated with shRNA targeted to Akt or EGFR or PKC $\delta$ or control scrambled shRNA. Moreover, they were pretreated with LY294002 $(25 \mu \mathrm{M}), \mathrm{GF109203X}(10 \mu \mathrm{M})$, Gö6976 $(10 \mu \mathrm{M})$, rottlerin $(10 \mu \mathrm{M})$, and AG1478 $(5 \mu \mathrm{M})$. They were maintained under static conditions or periodic mechanical stress for 3 days, $8 \mathrm{~h}$ per day, prior to direct cell counting and CCK-8 assay, respectively. In the second step, the cells were pretreated with shRNA targeted to 


\section{Cellular Physiology Cell Physiol Biochem 2016;39:1281-1294 \begin{tabular}{l|l|l} 
and Biochemistry $10.1159 / 000447833$ & $\begin{array}{l}\text { DO } 2016 \text { The Author(s). Published by S. Karger AG, Basel } \\
\text { Published online: September 08, } 2016\end{array}$ \\
www.karger.com/cpb
\end{tabular} \\ He et al.: PKC $\delta$-Dependent EGFR Mitogenic Signals via PI3K-Akt and ERK1/2}

Akt or EGFR or PKC $\delta$ or control scrambled shRNA. Moreover, they were pretreated with LY294002 $(25 \mu \mathrm{M})$, AG1478 $(5 \mu \mathrm{M})$, and rottlerin $(10 \mu \mathrm{M})$. They were maintained under static conditions or periodic mechanical stress for $1 \mathrm{~h}$ prior to Western blot analysis.

All groups of cells involved in the experiments were incubated at $37^{\circ} \mathrm{C}$ in the incubator with $5 \% \mathrm{CO}_{2}$.

\section{Western blot analysis}

Total protein was prepared using radioimmunoprecipitation assay (RIPA) buffer, and Western blot analyses were performed as previously described [25]. Total protein was prepared using RIPA buffer and analyzed for protein concentration using Bradford assay. Protein samples were resolved by sodium dodecyl sulfate polyacrylamide gel electrophoresis and transferred onto nitrocellulose membranes. Following blocking for $1 \mathrm{~h}$ with $5 \%$ milk in Tris-buffered saline and Tween 20, the membranes were incubated with antibodies (1:1000 dilution for three antibodies) overnight at $4^{\circ} \mathrm{C}$. The blots were then incubated with horseradish peroxidase-conjugated secondary antibody at room temperature for $1 \mathrm{~h}$ and developed colors with ECL. The results were scanned using Gel Imaging System (UVP Company, USA) and measured using Gel-Pro Analyzer software (Media Cybernetics, USA).

Proliferation Studies

Proliferation studies were assessed by two different methods: direct cell counting and CCK-8 assay.

\section{Direct cell counting}

The cells were trypsinized and counted as previously described [26]. The cell number was determined by counting each piece of glass slide independently. Each group included six random pieces of glass slides and the experiments were repeated five times.

CCK-8 assay

Cell proliferation was determined by using CCK-8 solution according to the manufacturer's instruction as previously described [27]. The cells were kept in five 96-well plates ( $\mathrm{n}=5$ ); $10 \mu \mathrm{L}$ of CCK-8 solution was added to each well and incubated for $4 \mathrm{~h}$ at $37^{\circ} \mathrm{C}$. The absorbance of each well was finally determined at 450 nm using a microplate reader.

\section{Statistical analysis}

Statistical analyses were performed using SPSS 14.0 software (SPSS, IL, USA), and the results were expressed as mean \pm standard deviation. Student's unpaired $t$ tests and one-way analysis of variance followed by post hoc Fisher's least significant difference tests were used to determine the statistical significance. A $P$ value of 0.05 was considered to be significant.

\section{Results}

PI3K-Akt and EGFR Are Required for Periodic Mechanical Stress-initiated Chondrocyte Proliferation

PI3K-Akt and EGFR inhibition with their selective inhibitors (LY294002 and AG1478) and targeted shRNA both blocked periodic mechanical stress-induced chondrocyte proliferation compared with chondrocytes in the control groups in response to periodic mechanical stress $(P<0.05$ for each, Fig. 1 and $3, n=5)$.

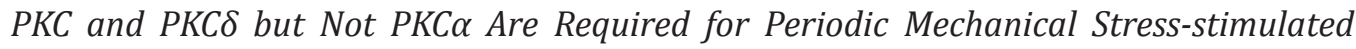
Chondrocyte Proliferation

Pretreatment with the selective inhibitors (GF109203X and rottlerin) and shRNA targeted to PKC $\delta$ prevented periodic mechanical stress-stimulated chondrocyte proliferation compared with chondrocytes in the control groups $(P<0.05$ for each, Fig. 2 and $3, n=5)$. But PKC $\alpha$ inhibition with Gö6976not did not suppress periodic mechanical stress-induced chondrocytes proliferation compared with the control group $(P>0.05$, Fig. $2, n=5)$. 
Fig. 1. Effects of PI3K-Akt and EGFR on chondrocyte proliferation under conditions of periodic mechanical stress (inhibitors). After pretreatment with DMSO or PI3K-Akt-selective inhibitor LY294002 $(25 \mu \mathrm{M})$, and EGFR selective inhibitor AG1478 $(5 \mu \mathrm{M})$, rat chondrocytes were cultured for 3 days under static conditions or conditions of periodic mechanical stress $8 \mathrm{~h}$ per day prior to proliferation studies. Chondrocyte proliferation was analyzed using direct cell counting (A) and CCK-8 assay (B). Chondrocyte proliferation results are shown in the histogram ( $n=5,{ }^{*} P<0.05$ for each). Chondrocyte proliferation in the selective inhibitor pretreatment groups significantly decreased relative to that in the control groups under conditions of periodic mechanical stress. ( $n=5, P<0.05$ for each; one-way analysis of variance followed by the post hoc Fisher's least significant difference test).

Fig. 2. Effects of $P K C, P K C \alpha$, and PKC $\delta$ on chondrocyte proliferation under conditions of periodic mechanical stress (inhibitors). After pretreatment with DMSO or PKC selective inhibitor GF109203X $(10 \mu \mathrm{M})$, PKC $\alpha$ selective inhibitor Gö6976 $(10 \mu \mathrm{M})$, and $\mathrm{PKC} \delta$ selective inhibitor rottlerin $(10 \mu \mathrm{M})$, rat chondrocytes were cultured for 3 days under static conditions or conditions of periodic mechanical stress $8 \mathrm{~h}$ per day prior to proliferation studies. Chondrocyte proliferation was analyzed using direct cell counting (A) and CCK-8 assay (B). Chondrocyte proliferation results are shown in the histogram ( $n$ $=5, * P<0.05$ for each). Chondrocyte proliferation significantly decreased in the GF109203X and rottlerin pretreatment groups $(n=5, P<0.05$ for each; one-way analysis of variance followed by the post hoc Fisher's least significant difference test) but not in the Gö6976 pretreatment group $(n=5, P>0.05$ for each; one-way analysis of variance followed by the post hoc Fisher's least significant difference test) relative to that in the control groups under conditions of periodic mechanical stress.
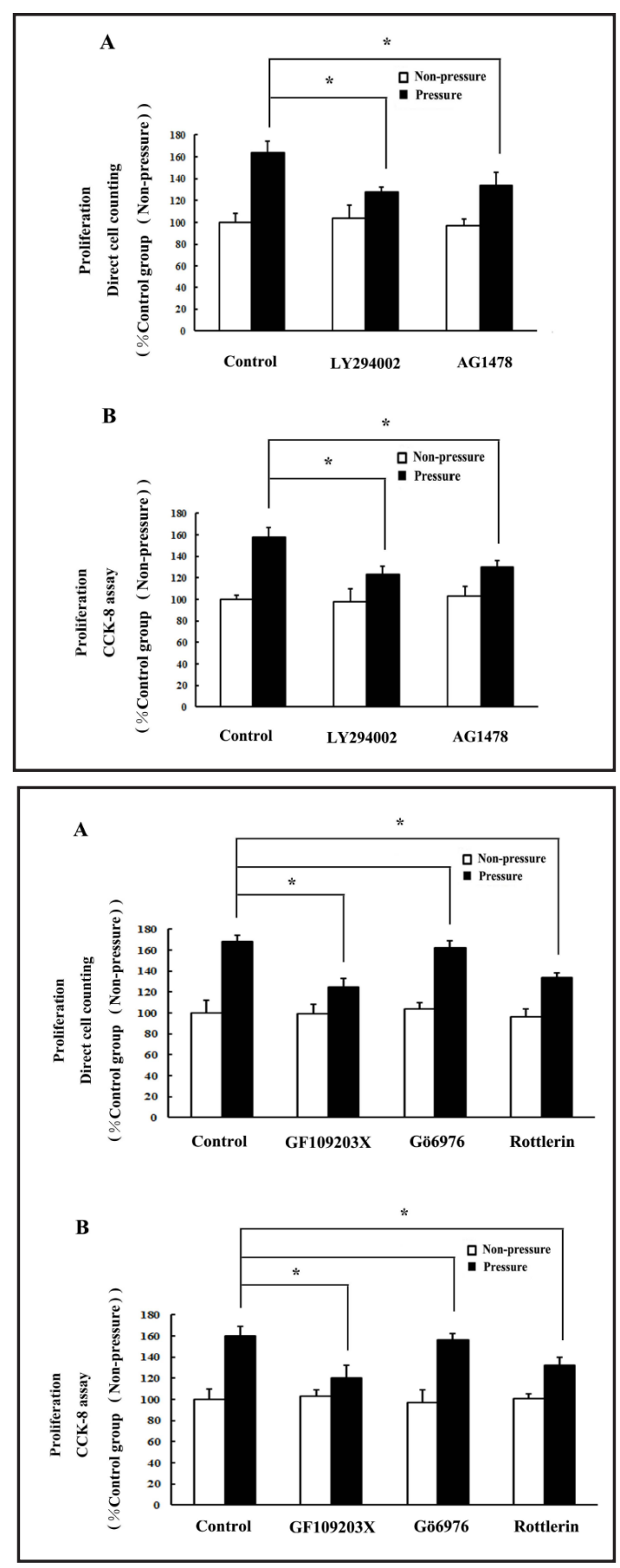

PI3K-Akt Inhibition Prevents Periodic Mechanical Stress-induced ERK1/2 Phosphorylation

PI3K-Akt inhibition by LY294002 pretreatment and shRNA targeted to Akt both abrogated the levels of ERK1/2 phosphorylation in chondrocytes under conditions of mechanical stress $(P<0.05$ for each, Fig. 4 and $5, n=5)$.

PI3K-Akt Is Not Required for Periodic Mechanical Stress-induced EGFR or PKCD Phosphorylation

Inhibition of PI3K-Akt with the selective inhibitor LY294002 and shRNA targeted to Akt did not reduce periodic mechanical stress-induced EGFR or PKC $\delta$ activation in chondrocytes under mechanical conditions ( $P>0.05$ for each, not shown, $n=5)$. 


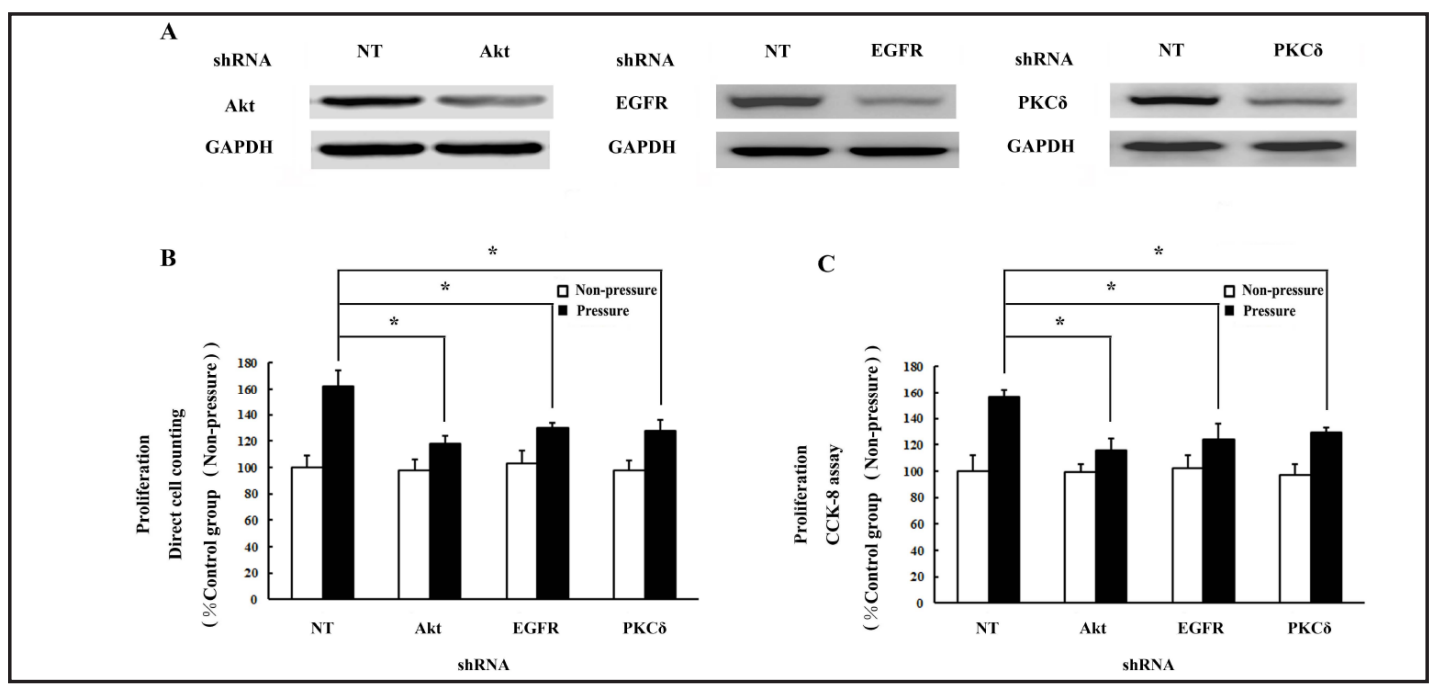

Fig. 3. Effects of PI3K-Akt, EGFR, and PKC $\delta$ on chondrocyte proliferation under conditions of periodic mechanical stress (shRNA). Chondrocytes were transfected with shRNA targeted to Akt or EGFR or PKC $\delta$ or with nontargeting sequences prior to lysis and Western blotting for Akt, EGFR, and PKC $\delta$ proteins. Transfection with shRNA for Akt, EGFR, and PKC $\delta$ achieved about a 50\% reduction in Akt, EGFR, and PKC $\delta$ protein levels, respectively (A). After pretreatment with control or Akt shRNA or EGFR shRNA or PKC $\delta$ shRNA, rat chondrocytes were cultured for 3 days under static conditions or conditions of periodic mechanical stress $8 \mathrm{~h}$ per day prior to proliferation studies. Chondrocyte proliferation was analyzed using direct cell counting (B) and CCK-8 assay (C). Chondrocyte proliferation results are shown in the histogram $(n=5, * P<0.05$ for each). Chondrocyte proliferation significantly decreased in the shRNA pretreatment groups relative to that in the control groups under conditions of periodic mechanical stress $(n=5, P>0.05$ for each; one-way analysis of variance followed by the post hoc Fisher's least significant difference test).

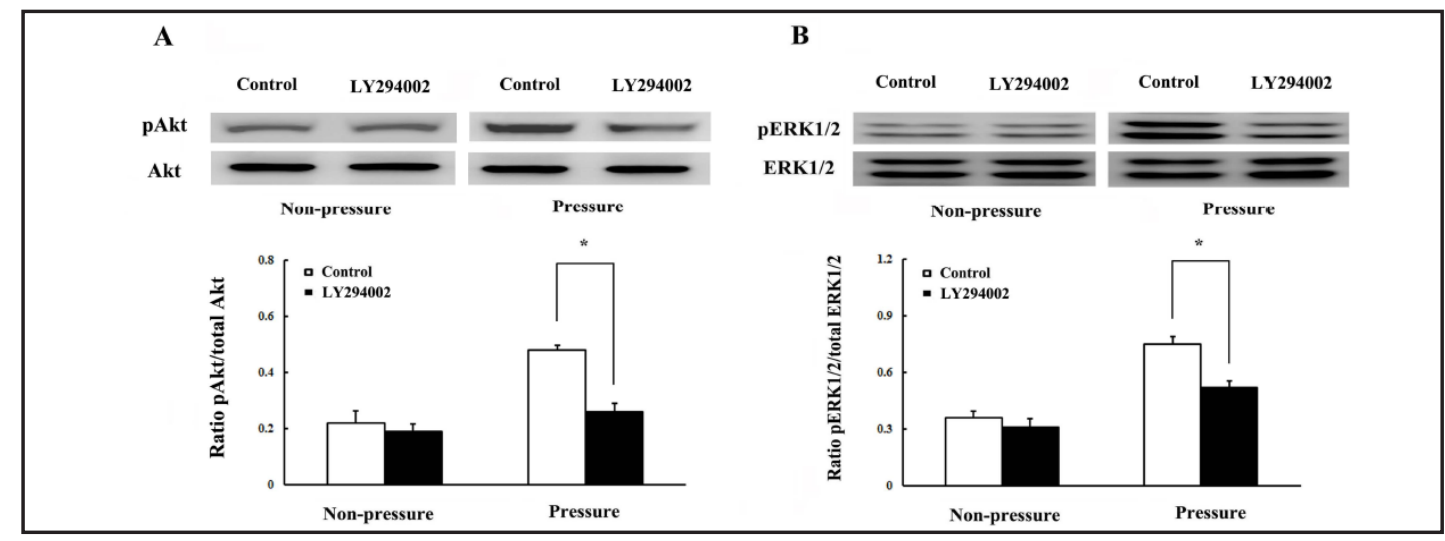

Fig. 4. Effects of PI3K-Akt on the phosphorylation of ERK1/2 under conditions of periodic mechanical stress (LY294002). After pretreatment with DMSO or PI3K-Akt inhibitor, rat chondrocytes were cultured in vitro for $1 \mathrm{~h}$ with or without periodic mechanical stress. The expression and phosphorylation levels of Akt and ERK1/2 were detected by Western blotting. The total amount of protein served as a control. Gray values are represented with a histogram $\left(n=5,{ }^{*} P<0.05\right.$ for each). The aforementioned images are representative results of Western blotting. The phosphorylation levels of Akt-Ser ${ }^{473}$ and ERK1/2-Thr ${ }^{202} / \mathrm{Tyr}^{204}$ in the PI3K-Akt-selective inhibitor pretreatment group were significantly decreased relative to those of the control group under conditions of periodic mechanical stress ( $n=5, P<0.05$ for each; Student's unpaired $t$ test).

\section{EGFR Is Required for Periodic Mechanical Stress-induced PI3K-Akt and ERK1/2 Phosphorylation}

Relative to that in the control group, the phosphorylation levels of Akt and ERK1/2 significantly decreased after treatment with AG1478 and shRNA targeted to EGFR in response to periodic mechanical stress $(P<0.05$ for each, Fig. 6 and $7, n=5)$.

\section{KARGER}


Fig. 5. Effects of PI3K-Akt on the phosphorylation of ERK1/2 under conditions of periodic mechanical stress (Akt shRNA). After pretreatment with control or Akt shRNA, rat chondrocytes were cultured in vitro for $1 \mathrm{~h}$ with or without periodic mechanical stress. The expression and phosphorylation levels of ERK1/2 were detected by Western blotting. The total amount of protein served as a control. Gray values are represented with a histogram $(n=5, * P<0.05$ for each). The aforementioned images are representative results of Western blotting. The phosphorylation levels of ERK1/2-Thr ${ }^{202} / \mathrm{Tyr}^{204}$ in the Akt shRNA pretreatment group significantly decreased relative to

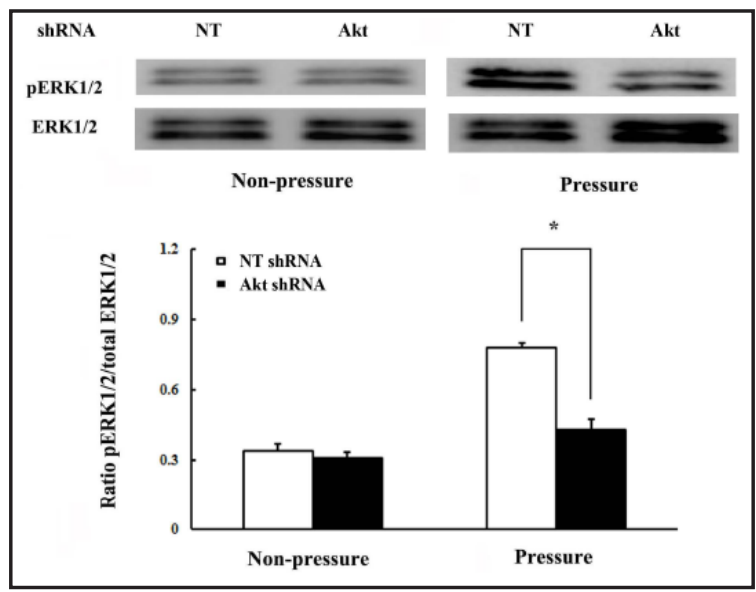
those of the control group under conditions of periodic mechanical stress $(n=5, P<0.05$ for each; Student's unpaired $t$ test).

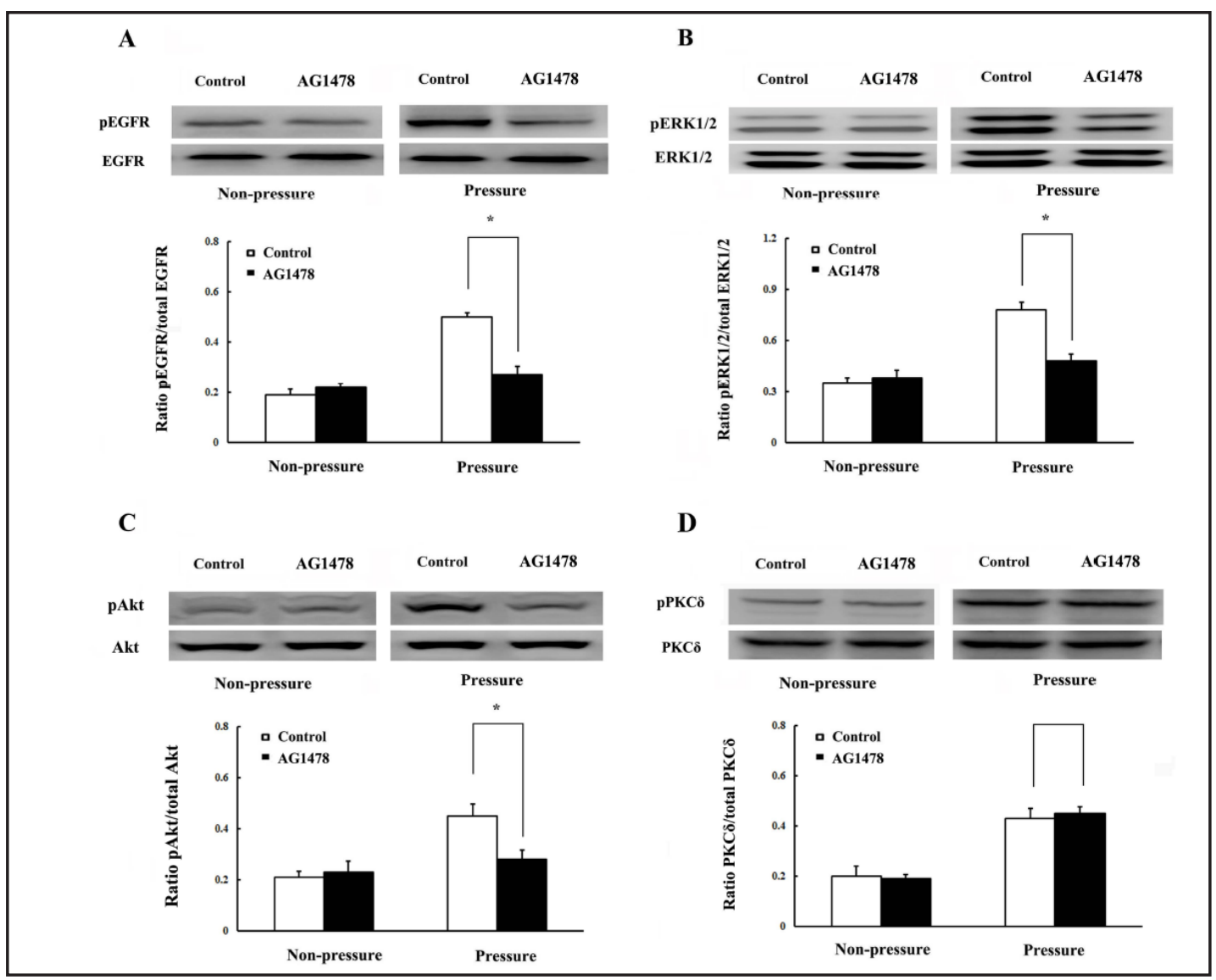

Fig. 6. Effects of EGFR on the expression and phosphorylation of PKC $\delta$, Akt, and ERK1/2 under conditions of periodic mechanical stress (AG1478). After pretreatment with DMSO or EGFR inhibitors AG1478, rat chondrocytes were cultured in vitro for $1 \mathrm{~h}$ with or without periodic mechanical stress. The expression and phosphorylation levels of EGFR, PKC $\delta$, Akt, and ERK1/2 were detected by Western blotting. The total amount of each protein served as a control. Gray values are represented with a histogram $\left(n=5,{ }^{*} P<0.05\right.$ for each). The aforementioned images are representative results of Western blotting. The phosphorylation levels of EGFR-Tyr ${ }^{1068}$, Akt-Ser ${ }^{473}$, and ERK1/2-Thr ${ }^{202} / \mathrm{Tyr}^{204}$ in the AG1478 pretreatment group significantly decreased relative to those of the control group under conditions of periodic mechanical stress $(n=5, P<$ 0.05 for each; Student's unpaired $t$ test), whereas the activation of PKC $\delta$-Thr ${ }^{507}$ in the AG1478 pretreatment group was not affected ( $n=5, P>0.05$ for each; Student's unpaired $t$ test). 


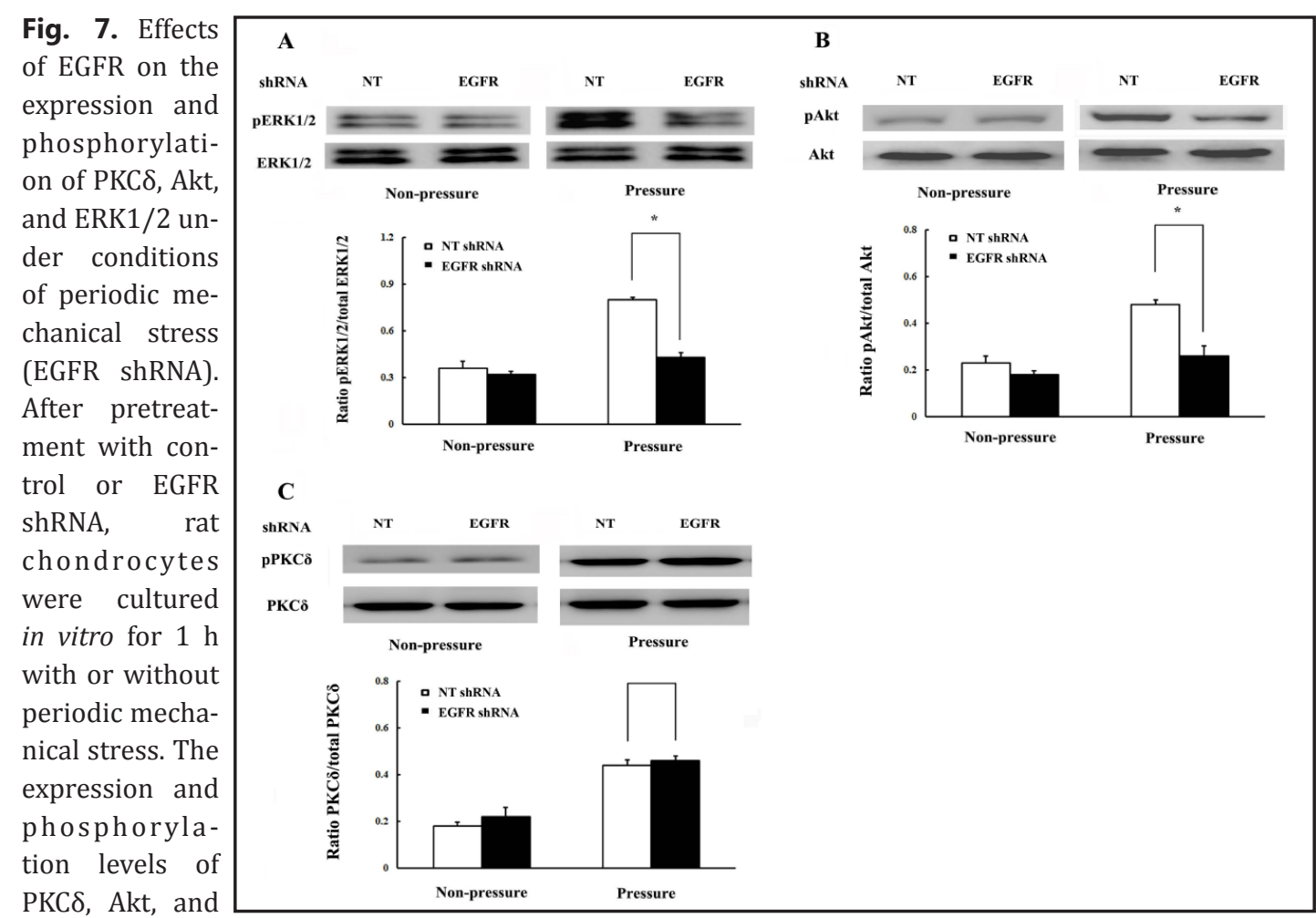

ERK1/2 were detected by Western blotting. The total amount of each protein served as a control. Gray values are represented with a histogram $n=5,{ }^{*} P<0.05$ for each). The aforementioned images are representative results of Western blotting. The phosphorylation levels of EGFR-Tyr ${ }^{1068}$, Akt-Ser ${ }^{473}$ and ERK1/2-Thr ${ }^{202}$ / $\mathrm{Tyr}^{204}$ in the EGFR shRNA pretreatment group significantly decreased relative to those of the control group under conditions of periodic mechanical stress ( $n=5, P<0.05$ for each; Student's unpaired $t$ test), whereas the activation of PKC $\delta$-Thr ${ }^{507}$ in the EGFR shRNA pretreatment group was not affected $(n=5, P>0.05$ for each; Student's unpaired $t$ test).

\section{EGFR Is Not Required for Periodic Mechanical Stress-induced PKC Phosphorylation}

Inhibition of EGFR with its selective inhibitor AG1478 and shRNA targeted to EGFR did not block periodic mechanical stress-induced PKC $\delta$ activation in chondrocytes under mechanical stress $(P>0.05$ for each, Fig. 6 and $7, n=5)$.

PKCS Is Required for Periodic Mechanical Stress-induced EGFR, PI3K-Akt and ERK1/2 Phosphorylation

Pretreatment with PKC $\delta$ selective inhibitor rottlerin and shRNA targeted to PKC $\delta$ both attenuated periodic mechanical stress-induced EGFR, Akt, and ERK1/2 phosphorylation in chondrocytes under conditions of periodic mechanical stimulation $(P<0.05$ for each, Fig. 8 and $9, n=5$ ).

\section{Discussion}

Periodic mechanical stress induction of chondrocyte proliferation may be mediated through a process of mechanotransduction, converting physical forces into biochemical signals and integrating these signals into cellular responses. The present findings indicated that PKC $\delta$, EGFR, and PI3K-Akt mediate the ERK1/2 mitogenic signaling cascade in chondrocytes in response to periodic mechanical stress.

PI3K-Akt signals could respond to mechanical stimuli and modulate proliferation in several nonchondrocytic cell types $[28,29]$. This study investigated and considered PI3KAkt signals to be candidate signals for inducing chondrocyte proliferation by periodic KARGER 
A

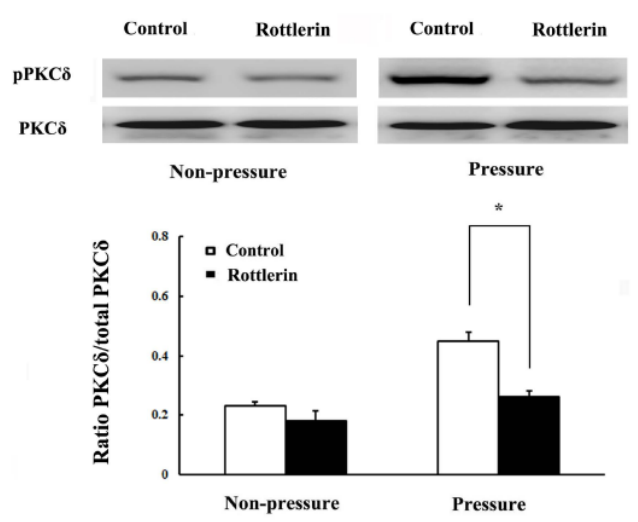

C

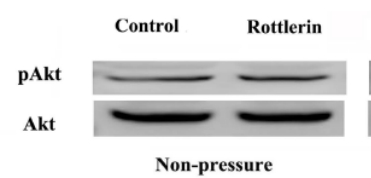

Non-pressure

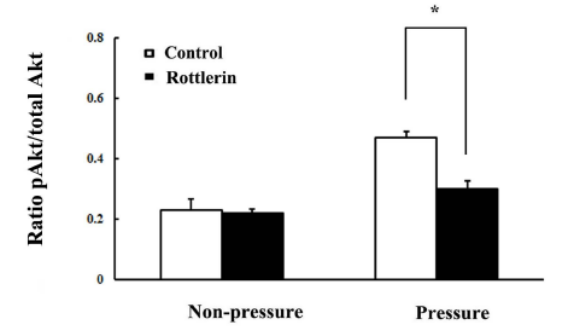

B

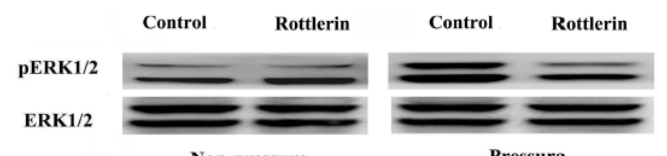

Non-pressure

Pressure

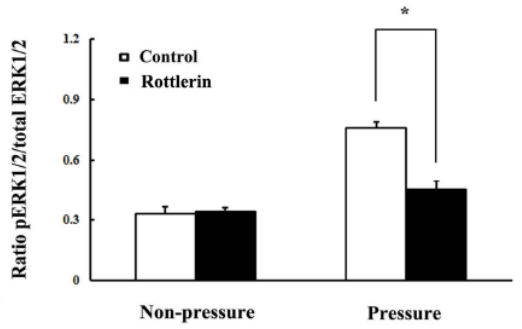

D
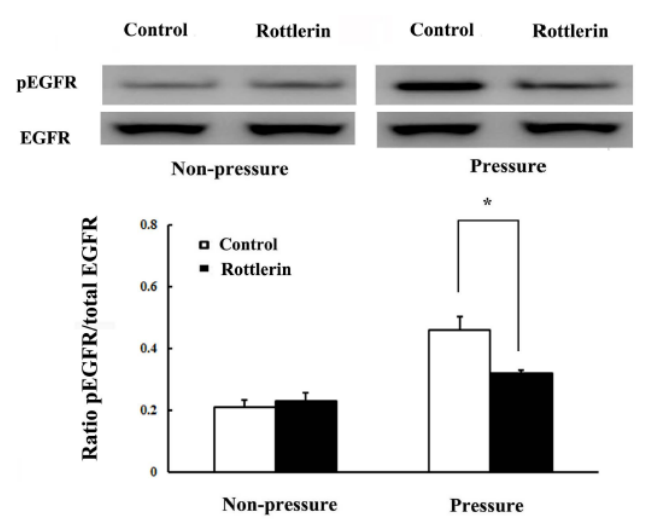

Fig. 8. Effects of PKC $\delta$ on the expression and phosphorylation of EGFR, Akt, and ERK1/2 under conditions of periodic mechanical stress (rottlerin). After pretreatment with DMSO or PKC $\delta$ inhibitor rottlerin, rat chondrocytes were cultured in vitro for $1 \mathrm{~h}$ with or without periodic mechanical stress. The expression and phosphorylation levels of PKC $\delta$, EGFR, Akt, and ERK1/2 were detected by Western blotting. The total amount of each protein served as a control. Gray values are represented with a histogram $\left(n=5,{ }^{*} P<0.05\right.$ for each). The aforementioned images are representative results of Western blotting. The phosphorylation levels of PKC $\delta$-Thr ${ }^{507}$, EGFR-Tyr ${ }^{1068}$, Akt-Ser ${ }^{473}$, and ERK1/2-Thr ${ }^{202} / \mathrm{Tyr}^{204}$ in the PKC $\delta$ selective inhibitor pretreatment group significantly decreased relative to those of the control group under conditions of periodic mechanical stress ( $n=5, P<0.05$ for each; Student's unpaired $t$ test).

mechanical stress. Pretreatment with the selective inhibitors of PI3K-Akt LY294002 and shRNA targeted to Akt significantly reduced chondrocyte proliferation under mechanical stress. The present results clearly indicated that the mitogenic effects induced by cyclic mechanical stimulation were at least partly mediated by the PI3K-Akt signals. This was the first study on the mechanosensing and signal transduction role of PI3K-Akt in chondrocytes. The findings are consistent with the results of some other studies and one report by Adam et al. that demonstrated that mechanical stretch stimulation of DNA synthesis in bladder smooth muscle cells was induced by activation via PI3K-Akt signaling [30, 31].

PI3K-Akt could modulate the activity and functions of multiple downstream effectors [32, 33]. In the present study, the activation of ERK1/2 was found to be attenuated as well when the activity of PI3K-Akt was inhibited by LY294002 or shRNA targeted to Akt, suggesting that the PI3K-Akt signal was required for the activation of ERK1/2 under conditions of mechanical stimulation. This finding was consistent with the work of Lee and colleagues that oscillatory shear stress induced osteoblast proliferation through ERK1/2, and the latter depended on 


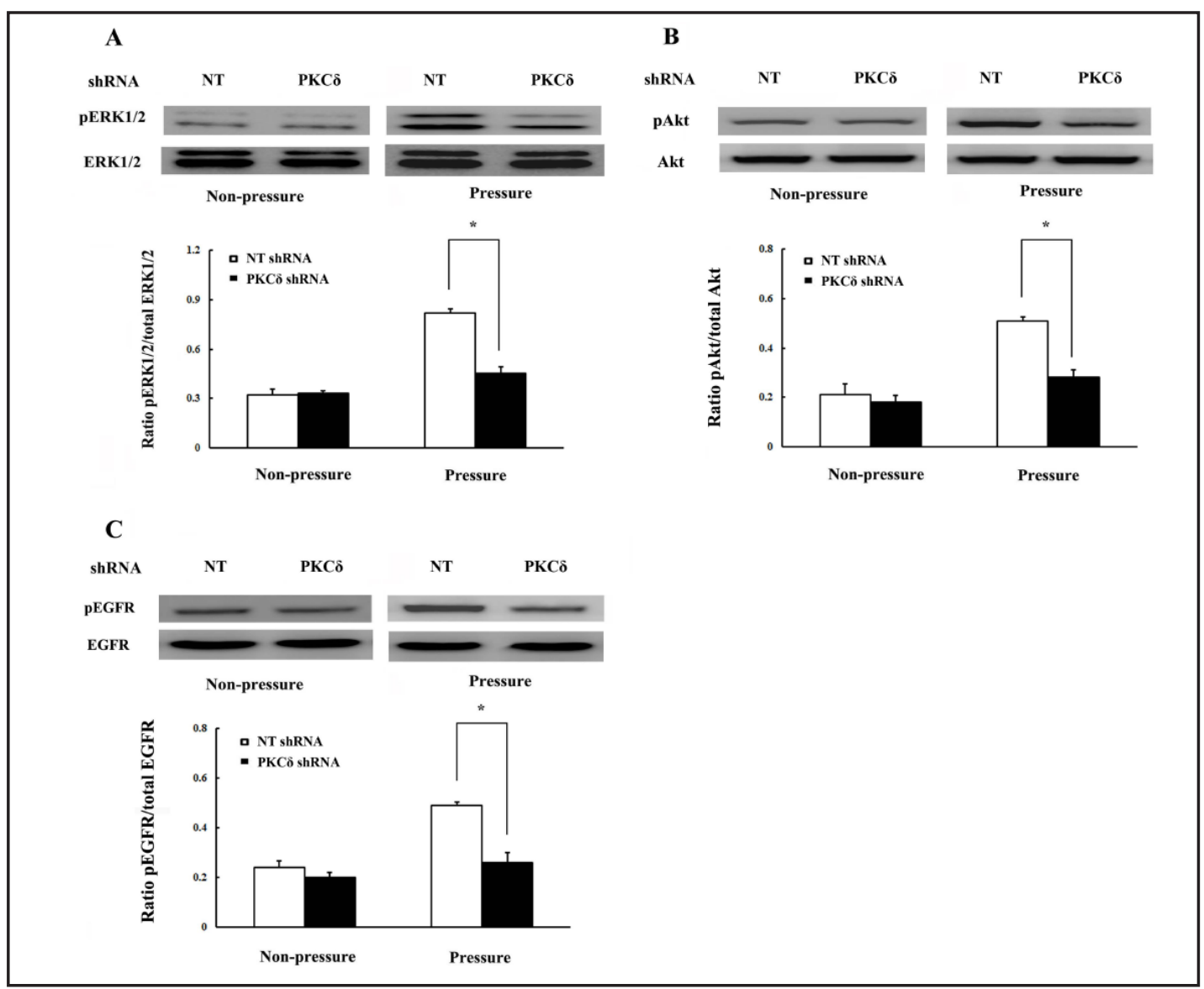

Fig. 9. Effects of PKC $\delta$ on the expression and phosphorylation of EGFR, Akt, and ERK1/2 under conditions of periodic mechanical stress (PKC $\delta$ shRNA). After pretreatment with control or PKC $\delta$ shRNA, rat chondrocytes were cultured in vitro for $1 \mathrm{~h}$ with or without periodic mechanical stress. The expression and phosphorylation levels of EGFR, Akt, and ERK1/2 were detected by Western blotting. The total amount of each protein served as a control. Gray values are represented with a histogram $(n=5, * P<0.05$ for each). The aforementioned images are representative results of Western blotting. The phosphorylation levels of EGFR-Tyr ${ }^{1068}$, Akt-Ser ${ }^{473}$ and ERK1/2-Thr ${ }^{202} / \mathrm{Tyr}^{204}$ in the PKC $\delta$ shRNA pretreatment group were significantly decreased relative to those of the control group under conditions of periodic mechanical stress $(n=5, P<$ 0.05 for each; Student's unpaired $t$ test).

the PI3K-Akt pathway [6]. Meanwhile, the activation of EGFR and PKC $\delta$ was not found to be affected after the inhibition of PI3K-Akt under the same conditions, suggesting that PI3K-Akt signals might not be required for the activity of EGFR and PKC $\delta$. The present data supported that the PI3K-Akt signal, which was located upstream of ERK1/2, was responsible for the upregulation of chondrocyte proliferation by periodic mechanical stress.

EGFR, as a nonintegrin mechanosensor, could mediate mechanical responses, and the reports that EGF-EGFR induced chondrocyte proliferation prompted investigation to examine the involvement of EGFR in the periodic mechanical stress-induced chondrocytic mitogenic effects $[34,35]$. The present study showed that the specific EGFR inhibitor AG1478 and shRNA targeted to EGFR blocked chondrocyte proliferation in response to periodic mechanical stress. The results strongly implicated for the first time EGFR kinase signaling in the chondrocytic mitogenic response to periodic mechanical stress. This was consistent with other observations that EGFR mediated the mechanotransduced mitogenic effects in human bronchial epithelial cells, as well as in vascular smooth muscle cells [36, 37]. Despite the importance of EGFR in mediating chondrocyte proliferation, it is possible that other growth factor receptors may also play a role under conditions of mechanical stimuli.

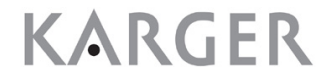




\section{Cellular Physiology Cell Physiol Biochem 2016;39:1281-1294 \begin{tabular}{l|l|l} 
and Biochemistry.1159/000447833 & $\begin{array}{l}\text { (C) 2016 The Author(s). Published by S. Karger AG, Basel } \\
\text { www.karger.com/cpb }\end{array}$
\end{tabular} \\ He et al.: PKC 8 -Dependent EGFR Mitogenic Signals via PI3K-Akt and ERK1/2}

A number of autophosphorylation sites have been identified in the intracellular domain of EGFR, which allow for specific binding and activation of downstream signaling molecules $[38,39]$. The activation of ERK1/2 and PI3K by EGFR has recently been demonstrated to be a signaling transduction mechanism in SNU-407 colon cancer cells and MH1C1 cells $[40,41]$. The present study found that inhibition of EGFR with AG1478 and shRNA targeted to EGFR prevented the activation of Akt and ERK1/2, suggesting functional links between EGFR and PI3K-Akt/ERK1/2 signaling. EGFR may be a key upstream regulator of these cyclic mechanical stimuli-induced signals in this model. This study also observed that the activation of PKC $\delta$ was not reduced after pretreatment with AG1478 under the same conditions, suggesting that EGFR might not be located upstream of PKC $\delta$. Hence, it could be concluded that EGFR mediated at least some mitogenic mechanotransduced signals through PI3K-Akt and ERK1/2 in chondrocytes.

Increasing evidence showed that PKC played an important role in the signal transduction cascades in response to mechanical stimulation through the phosphorylation of hydroxyl groups of serine and threonine amino acid residues on

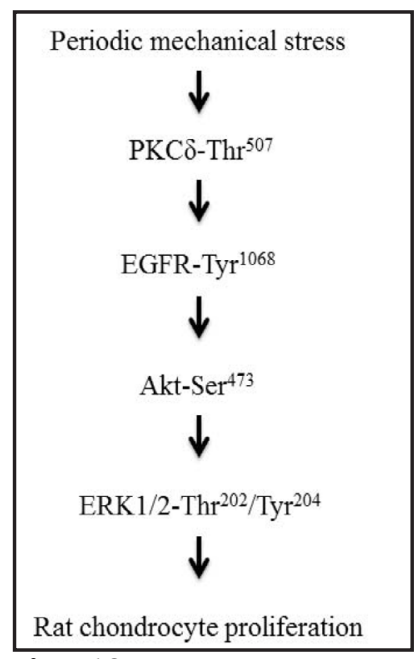

Fig. 10. Schematic diagram of the signal transduction pathway of rat chondrocyte proliferation induced by periodic mechanical stress. these proteins $[9,42]$. The present study found that inhibition of PKC and PKC $\delta$ abrogated chondrocyte proliferation in chondrocytes in response to mechanical stress. Also, the mitogenic effects initiated by mechanical stress were not affected after pretreatment with PKC $\alpha$ inhibitor Gö6976. These results clearly showed that PKC $\delta$ played a key role in the regulation of the mitogenic responses to periodic mechanical stimuli in chondrocytes. Coincidentally, the study by Han demonstrated a similar phenomenon that cyclically mechanical strain induced Caco- 2 intestinal epithelial proliferation via the PKC signal [43]. Hence, it could be concluded that PKC $\delta$ played a key role in chondrocytic adaption to physical mechanical stimulation.

Some studies showed that EGFR was required for PKC activation in other cell types in response to various stimuli $[44,45]$. Interestingly, instead of being activated by an EGFRdependent mechanism, the inhibition of cyclic mechanical stress-stimulated EGFR by rottlerin or shRNA targeted to PKC $\delta$ suggested that PKC $\delta$ might be responsible for the initial EGFR activation in the present study. PKC has also been reported to be located upstream of EGFR in response to several stimuli in different cell culture systems in diverse complex signaling pathways $[46,47]$. These differences likely reflect differences in not only cell type but also the nature of the stimulus. A further observation that $\mathrm{PKC} \delta$ is required for mechanotransduced PI3K-Akt and ERK1/2 activation seems consistent with the reports of PKC interactions with PI3K-Akt and ERK1/2 in other cell types [48, 49]. However, this relationship has not been investigated in chondrocytes under mechanical stimulation. These data suggest that PKC $\delta$ might be a proximal kinase in the signaling pathway that leads, through EGFR and PI3K-Akt, to the increased ERK1/2 activation and chondrocyte proliferation in response to periodic mechanical stress.

In conclusion, the present study found that periodic mechanical stress could stimulate the phosphorylation of PKC $\delta$, which in turn activated EGFR. Activated EGFR led to ERK1/2 mitogenic signaling cascade via regulating the activity of PI3K-Akt in chondrocytes. Thus, PKC -EGFR-PI3K-Akt-ERK1/2 constituted at least one critical signal transduction pathway for chondrocyte proliferation induced by periodic mechanical stress. These results of our previous studies and the present study provide a stronger viewpoint for further investigations into chondrocyte mechanobiology under periodic mechanical stress and the way to improve the quality of tissue-engineered cartilage (Fig. 10). 


\section{Cellular Physiology Cell Physiol Biochem 2016;39:1281-1294

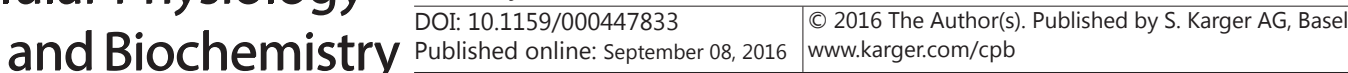

He et al.: PKC $\delta$-Dependent EGFR Mitogenic Signals via PI3K-Akt and ERK1/2

\section{Acknowledgments}

This work was supported by the National Natural and Science Foundation (81501874) and Jiangsu Province Health and Family Planning Commission Foundation (Q201511) (all foundations to Kewei Ren).

\section{Disclosure Statement}

The authors declare that they have no competing interests.

\section{References}

1 Wang PY, Chow HH, Lai JY, Liu HL, Tsai WB: Dynamic compression modulates chondrocyte proliferation and matrix biosynthesis in chitosan/gelatin scaffolds. J Biomed Mater Res B Appl Biomater 2009;91:143152.

2 Liang W, Zhu C, Liu F, Cui W, Wang Q, Chen Z, Zhou Q, Xu S, Zhai C, Fan W: Integrin beta1 gene therapy enhances in vitro creation of tissue-engineered cartilage under periodic mechanical stress. Cell Physiol Biochem 2015;37:1301-1314.

3 Fan QW, Weiss WA: Targeting the rtk-pi3k-mtor axis in malignant glioma: Overcoming resistance. Curr Top Microbiol Immunol 2010;347:279-296.

4 Bar-Lev TH, Harris D, Tomic M, Stojilkovic S, Blumenfeld Z, Brown P, Seger R, Naor Z: Role of pi4k and pi3kakt in erk1/2 activation by gnrh in the pituitary gonadotropes. Mol Cell Endocrinol 2015;415:12-23.

5 Xue H, Tu Y, Ma T, Liu X, Wen T, Cai M, Xia Z, Mei J: Lactoferrin inhibits il-1beta-induced chondrocyte apoptosis through akt1-induced creb1 activation. Cell Physiol Biochem 2015;36:2456-2465.

6 Lee DY, Li YS, Chang SF, Zhou J, Ho HM, Chiu JJ, Chien S: Oscillatory flow-induced proliferation of osteoblastlike cells is mediated by alphavbeta3 and beta1 integrins through synergistic interactions of focal adhesion kinase and shc with phosphatidylinositol 3-kinase and the akt/mtor/p70s6k pathway. J Biol Chem 2010;285:30-42.

7 Gayer CP, Chaturvedi LS, Wang S, Craig DH, Flanigan T, Basson MD: Strain-induced proliferation requires the phosphatidylinositol 3-kinase/akt/glycogen synthase kinase pathway. J Biol Chem 2009;284:20012011.

8 Wang Y, Zhu L, Kuokkanen S, Pollard JW: Activation of protein synthesis in mouse uterine epithelial cells by estradiol-17beta is mediated by a pkc-erk1/2-mtor signaling pathway. Proc Natl Acad Sci U S A 2015;112:E1382-1391.

9 Momberger TS, Levick JR, Mason RM: Mechanosensitive synoviocytes: A ca2 + -pkcalpha-map kinase pathway contributes to stretch-induced hyaluronan synthesis in vitro. Matrix Biol 2006;25:306-316.

10 Motta EM, Calixto JB, Rae GA: Mechanical hyperalgesia induced by endothelin-1 in rats is mediated via phospholipase c, protein kinase c, and map kinases. Exp Biol Med (Maywood) 2006;231:1141-1145.

11 Liu M, Xu J, Liu J, Kraw ME, Tanswell AK, Post M: Mechanical strain-enhanced fetal lung cell proliferation is mediated by phospholipase c and d and protein kinase c. Am J Physiol 1995;268:L729-738.

12 Sun H, Li G, Zhang W, Zhou Q Yu Y, Shi Y, Offermanns S, Lu J, Zhou N: Niacin activates the pi3k/akt cascade via pkc- and egfr-transactivation-dependent pathways through hydroxyl-carboxylic acid receptor 2. PLoS One 2014;9:e112310.

13 Chin CC, Li JM, Lee KF, Huang YC, Wang KC, Lai HC, Cheng CC, Kuo YH, Shi CS: Selective beta2-ar blockage suppresses colorectal cancer growth through regulation of egfr-akt/erk1/2 signaling, g1-phase arrest, and apoptosis. J Cell Physiol 2015

14 Zhuang S, Dang Y, Schnellmann RG: Requirement of the epidermal growth factor receptor in renal epithelial cell proliferation and migration. Am J Physiol Renal Physiol 2004;287:F365-372.

15 Kippenberger S, Loitsch S, Guschel M, Muller J, Knies Y, Kaufmann R, Bernd A: Mechanical stretch stimulates protein kinase b/akt phosphorylation in epidermal cells via angiotensin ii type 1 receptor and epidermal growth factor receptor. J Biol Chem 2005;280:3060-3067. 


\section{Cellular Physiology Cell Physiol Biochem 2016;39:1281-1294 \begin{tabular}{l|l|l|l|l} 
DOI: 10.1159/000447833 & $\begin{array}{l}\text { C } 2016 \text { The Author(s). Published by S. Karger AG, Basel } \\
\text { www.karger.com/cpb }\end{array}$
\end{tabular} \\ He et al.: PKCס-Dependent EGFR Mitogenic Signals via PI3K-Akt and ERK1/2}

16 Yano S, Komine M, Fujimoto M, Okochi H, Tamaki K: Mechanical stretching in vitro regulates signal transduction pathways and cellular proliferation in human epidermal keratinocytes. J Invest Dermatol 2004;122:783-790.

17 Pan SN, Ma HM, Su Z, Zhang CX, Zhu SY, Du ML: Epidermal growth factor receptor signalling mediates growth hormone-induced growth of chondrocytes from sex hormone-inhibited adolescent rats. Clin Exp Pharmacol Physiol 2011;38:534-542.

18 Takeda H, Inoue H, Kutsuna T, Matsushita N, Takahashi T, Watanabe S, Higashiyama S, Yamamoto H: Activation of epidermal growth factor receptor gene is involved in transforming growth factor-betamediated fibronectin expression in a chondrocyte progenitor cell line. Int J Mol Med 2010;25:593-600.

19 Hwang YP, Yun HJ, Choi JH, Han EH, Kim HG, Song GY, Kwon KI, Jeong TC, Jeong HG: Suppression of egfinduced tumor cell migration and matrix metalloproteinase- 9 expression by capsaicin via the inhibition of egfr-mediated fak/akt, pkc/raf/erk, p38 mapk, and ap-1 signaling. Mol Nutr Food Res 2011;55:594-605.

20 Xu R, Shang C, Zhao J, Han Y, Liu J, Chen K, Shi W: Activation of m3 muscarinic receptor by acetylcholine promotes non-small cell lung cancer cell proliferation and invasion via egfr/pi3k/akt pathway. Tumour Biol 2015;36:4091-4100.

21 Seguin CA, Bernier SM: Tnfalpha suppresses link protein and type ii collagen expression in chondrocytes: Role of mek1/2 and nf-kappab signaling pathways. J Cell Physiol 2003;197:356-369.

22 Nong L, Yin G, Ren K, Tang J, Fan W: Periodic mechanical stress enhances rat chondrocyte area expansion and migration through src-plcgamma1-erk1/2 signaling. Eur J Cell Biol 2010;89:705-711.

23 Yue HT, Fan WM, Ma YM: Tissue engineered cartilage in response to diferent cyclic pressure.Xpression in a pkc- andrho kinase-dependent manner. Chin J Orthop Trauma 2007;9:661-664.

24 Zhang GC, Fan WM: Effects of cyclic pressure at different frequendes on the construction of tissueengineering cartilage. Chin J Exp Surg 2007;24:677-678.

25 Wang P, Cao X, Nagel DJ, Yin G: Activation of ask1 during reperfusion of ischemic spinal cord. Neurosci Lett 2007;415:248-252.

26 Chaturvedi LS, Marsh HM, Shang X, Zheng Y, Basson MD: Repetitive deformation activates focal adhesion kinase and erk mitogenic signals in human caco-2 intestinal epithelial cells through src and rac1. J Biol Chem 2007;282:14-28.

27 Bae JY, Han DW, Wakitani S, Nawata M, Hyon SH: Biological and biomechanical evaluations of osteochondral allografts preserved in cold storage solution containing epigallocatechin gallate. Cell Transplant 2010;19:681-689.

28 Hu Z, Xiong Y, Han X, Geng C, Jiang B, Huo Y, Luo J: Acute mechanical stretch promotes enos activation in venous endothelial cells mainly via pka and akt pathways. PLoS One 2013;8:e71359.

29 Tian Y, Yue X, Luo D, Wazir R, Wang J, Wu T, Chen L, Liao B, Wang K: Increased proliferation of human bladder smooth muscle cells is mediated by physiological cyclic stretch via the pi3ksgk1 kv1.3 pathway. Mol Med Rep 2013;8:294-298.

30 Adam RM, Roth JA, Cheng HL, Rice DC, Khoury J, Bauer SB, Peters CA, Freeman MR: Signaling through pi3k/akt mediates stretch and pdgf-bb-dependent DNA synthesis in bladder smooth muscle cells. J Urol 2003;169:2388-2393.

31 Liu J, Agarwal S: Mechanical signals activate vascular endothelial growth factor receptor-2 to upregulate endothelial cell proliferation during inflammation. J Immunol 2010;185:1215-1221.

32 Shi H, Cheng Y, Ye J, Cai P, Zhang J, Li R, Yang Y, Wang Z, Zhang H, Lin C, Lu X, Jiang L, Hu A, Zhu X, Zeng Q, Fu $\mathrm{X}$, Li X, Xiao J: Bfgf promotes the migration of human dermal fibroblasts under diabetic conditions through reactive oxygen species production via the pi3k/akt-rac1- jnk pathways. Int J Biol Sci 2015;11:845-859.

33 Jeong W, Song G, Bazer FW, Kim J: Insulin-like growth factor i induces proliferation and migration of porcine trophectoderm cells through multiple cell signaling pathways, including protooncogenic protein kinase 1 and mitogen-activated protein kinase. Mol Cell Endocrinol 2014;384:175-184.

34 Bujia J: [effect of growth factors on cell proliferation and matrix synthesis in cultured human chondrocytes]. Laryngorhinootologie 1995;74:444-449.

35 Umesh V, Rape AD, Ulrich TA, Kumar S: Microenvironmental stiffness enhances glioma cell proliferation by stimulating epidermal growth factor receptor signaling. PLoS One 2015;9:e101771.

36 Iwasaki H, Eguchi S, Ueno H, Marumo F, Hirata Y: Mechanical stretch stimulates growth of vascular smooth muscle cells via epidermal growth factor receptor. Am J Physiol Heart Circ Physiol 2000;278:H521-529. 


\section{Cellular Physiology Cell Physiol Biochem 2016;39:1281-1294 \begin{tabular}{ll|l} 
DOI: 10.1159/000447833 & $\begin{array}{l}\text { O 2016 The Author(s). Published by S. Karger AG, Basel } \\
\text { www.karger.com/cpb }\end{array}$
\end{tabular} \\ He et al.: PKC $\delta$-Dependent EGFR Mitogenic Signals via PI3K-Akt and ERK1/2}

37 Li N, Li Q, Zhou XD, Kolosov VP, Perelman JM: Chronic mechanical stress induces mucin5ac expression in human bronchial epithelial cells through erk dependent pathways. Mol Biol Rep 2012;39:1019-1028.

38 Song X, Wei Z, Shaikh ZA: Requirement of eralpha and basal activities of egfr and src kinase in cd-induced activation of mapk/erk pathway in human breast cancer mcf-7 cells. Toxicol Appl Pharmacol 2015;287:2634.

39 Kim Y, Kim K, Park D, Eom S, Park H, Lee H, Lee YS, Choe J, Hahn JH, Kim YM, Ro JY, Jeoung D: Integrin alpha(5) interacts with egfr, is necessary for fcvarepsilonri signaling and is necessary for allergic inflammation in relation with angiogenesis. Mol Immunol 2011;48:1035-1045.

40 Park YS, Cho NJ: Egfr and pkc are involved in the activation of erk1/2 and p90 rsk and the subsequent proliferation of snu-407 colon cancer cells by muscarinic acetylcholine receptors. Mol Cell Biochem 2012;370:191-198.

41 Tveteraas IH, Muller KM, Aasrum M, Odegard J, Dajani O, Guren T, Sandnes D, Christoffersen T: Mechanisms involved in pge2-induced transactivation of the epidermal growth factor receptor in mh1c1 hepatocarcinoma cells. J Exp Clin Cancer Res 2012;31:72.

42 Traub O, Monia BP, Dean NM, Berk BC: Pkc-epsilon is required for mechano-sensitive activation of erk1/2 in endothelial cells. J Biol Chem 1997;272:31251-31257.

43 Han O, Li GD, Sumpio BE, Basson MD: Strain induces caco-2 intestinal epithelial proliferation and differentiation via pkc and tyrosine kinase signals. Am J Physiol 1998;275:G534-541.

44 Wu D, Peng F, Zhang B, Ingram AJ, Kelly DJ, Gilbert RE, Gao B, Kumar S, Krepinsky JC: Egfr-plcgamma1 signaling mediates high glucose-induced pkcbeta1-akt activation and collagen i upregulation in mesangial cells. Am J Physiol Renal Physiol 2009;297:F822-834.

45 Mukhopadhyay P, Lakshmanan I, Ponnusamy MP, Chakraborty S, Jain M, Pai P, Smith LM, Lele SM, Batra SK: Muc4 overexpression augments cell migration and metastasis through egfr family proteins in triple negative breast cancer cells. PLoS One 2013;8:e54455.

46 Yamashita Y, Okamoto M, Ikeda M, Okamoto A, Sakai M, Gunji Y, Nishimura R, Hishinuma M, Shimada M: Protein kinase c (pkc) increases tace/adam17 enzyme activity in porcine ovarian somatic cells, which is essential for granulosa cell luteinization and oocyte maturation. Endocrinology 2014;155:1080-1090.

47 Sutton P, Borgia JA, Bonomi P, Plate JM: Lyn, a src family kinase, regulates activation of epidermal growth factor receptors in lung adenocarcinoma cells. Mol Cancer 2013;12:76.

48 Yang CM, Hsieh HL, Yao CC, Hsiao LD, Tseng CP, Wu CB: Protein kinase c-delta transactivates platelet-derived growth factor receptor-alpha in mechanical strain-induced collagenase 3 (matrix metalloproteinase-13) expression by osteoblast-like cells. J Biol Chem 2009;284:26040-26050.

49 Norcini M, Vivoli E, Galeotti N, Bianchi E, Bartolini A, Ghelardini C: Supraspinal role of protein kinase c in oxaliplatin-induced neuropathy in rat. Pain 2009;146:141-147. 